\title{
A STUDY INTO FORCES AND MOMENTS ACTING ON THE SWASH PLATE OF AN AXIAL PISTON PUMP USING A NOVEL APPROACH TO REDUCE PRESSURE AND FLOW PULSATIONS.
}

\author{
Pratin J. Naik, Ganesh K. Seeniraj and Ram S. Chandran* \\ CNH Industrial, 6900 Veterns Blvd, Burr ridge, IL 60527 \\ CNH Industrial-technology, 200 George C Delp Road, New Holland PA 17557 \\ Mechanical Engineering Department, Kettering University, Flint, MI 48504 USA \\ * Corresponding author: Tel.: +1 810762 7839; E-mail address: rchandra@kettering.edu
}

\begin{abstract}
In hydraulic pumps, typically in axial piston pumps, reduction of pressure and flow ripples was attempted by providing relief grooves and pre-compression for noise reduction. Pre-compression is normally achieved by using the dead space between pump ports in the valve plate. Also valve plate profile modification is required, if system operating conditions such as pump output pressure and flowrate change, to maintain optimum operating conditions for reduced pressure/flow ripple. An earlier simulation study confirmed effectiveness of varying dead centre position to reduce pressure and flow ripples. A specifically designed mechanism, outlined in the earlier work, achieves this goal by varying the dead centre position of the pump swash plate. This study reports on the findings of the effect of varying dead centre position and groove configurations on forces and moments acting on the swash plate for various operating conditions. The simulation model cited in the earlier work was used in this study. This information is vital for the design of an actuating mechanism to vary dead centre position of a pump valve plate. These simulations were run using MATLAB/Simulink and S-functions. Results of this study are promising.
\end{abstract}

Keywords: Axial piston pump, simulation of an hydraulic pump, pressure and flow ripples and dead centers.

\section{INTRODUCTION}

For the past four decades, a large amount of work has been reported on modelling, design and control of axial piston hydraulic pumps. Most of the literature focuses mainly on mathematical modelling and design of pumps for performance improvement and control. An equal amount of material can also be found on noise generation in a hydraulic pump. The work presented in this paper is a continuation of an earlier work by Ganesh K Seeniraj and Ram Chandran [7]. This study presents results on forces and moments experienced by the swash plate when dead centre position and groove configurations are varied for various operating conditions. The same simulation model cited in the earlier work [7] was used in this study with some modifications. This information is vital for the design of an actuating mechanism to effect changes in dead centre position. The earlier paper [7] discusses a novel approach to minimize pressure and flow pulsations that may lead to reduction of noise generation in an axial piston swash plate pump.

Noise generation in an axial piston pump can be attributed to two main causes - "fluid causes and mechanical causes", according to Yamauchi and Yamamoto [8]. The mechanism of pumping action and the pressure variation inside piston volume are one of the main causes of noise generation. They relate to fluid causes through flow and pressure pulsations that propagate through the system and to mechanical causes by inducing cyclic strain causing pump components to vibrate.

The above said problem has been investigated by a number of other researchers in their unique way. Techniques adopted in noise reduction include providing relief grooves, precompression and ideal timing of the valve ports. These solutions introduce a major constraint on the controllability of a pump. i.e. the suggested 
solution is suited only for a fixed operating condition. The performance of a pump is thus fixed and cannot be varied during operation. This is a drawback the valve plate has to be matched for a required operating point and cannot be used in systems requiring variable flow.

In the work presented by Seeniraj and Chandran [7] the authors attempt to minimize pressure and flow pulsations by combining two well-known strategies: providing relief grooves and varying port opening and associated precompression. Pre-compression is varied by shifting the dead centre location of the piston with respect to the valve plate. One of the main advantages of this approach is it can be applied to a variable displacement pump. Pump performance can be varied in real time as opposed to fixed performance offered by previous solutions. The aim is to vary the dead centre position (both top and bottom) of the pistons and find an optimum condition to keep the amplitude of the flow ripple and pressure pulsations to a minimum.

Becker [1] studied noise generation related to pressure transients in piston-cylinder chambers and suggested port modification and providing metering grooves to reduce pressure peaks. This addresses noise generation attributed to fluid compression and decompression. Metering grooves facilitated smooth transition.

Helgestad et al [2] investigated pressure transients in an axial piston pump through theoretical and experimental examination of pressure profile within each piston-cylinder chamber. Main focus of their work was noise generation due to pressure fluctuations. Two methods were tried to reduce noise generation: (1) 'Ideal Timing' (23 degrees from B.D.C) i.e., opening the valve port exactly when the pressure inside the piston had reached the required discharge pressure and (2) Providing 'relief grooves' at the start of both suction and discharge ports. The relief grooves had a problem of reverse flow into the piston chamber from the discharge at low speeds and induced cavitation at the suction port at high speeds.

Pettersson et al [4] proposed a simple mathematical model for flow ripple simulation.

An important conclusion of their work was that a fairly simple model could be used for the study of effect of relief groove and pre-compression on pressure and flow pulsations. Pre-compression showed a remarkable impact on peak-to peak value of flow ripple.

Johansson [3] examined the effect of crossangle on pump noise due to pressure and flow pulsations. Cross-angle is an additional incline to the traditional displacement direction. With cross-angle the piston dead-centres vary as a function of displacement, swash plate angle, enabling pre-compression and decompression.

\section{PUMP MODEL, SIMULATION AND RESULTS}

The pump model used in this work is an extension of the model used by Seeniraj and Chandran [7] in their research. Their model was an adaptation from the earlier work by Schoenau, Burton and Kavanagh [6]. Numerical values of parameters were taken from the work presented by Zhang, Cho, Nair and Manring [9]. Equations and the numerical values of the parameters are listed in the appendix. This model includes additional expressions to evaluate forces and moments acting on the swash plate and pump drive torque.

The model uses prime mover speed as the input and outputs are: pressure inside each piston, flow rates into and out of each piston, flow ripple and pressure pulsation at the pump outlet, moment and force on the swash plate and drive torque at the pump shaft. These outputs facilitate the visualization of the effect of noise reduction technique(s) on pump variables. Results obtained using this model agrees with earlier results presented by other authors.

The model has provision to vary the groove length. Groove length was varied in steps of $25 \%$ of the full length from zero to full groove length. Other parameters that were varied include dead centre position and buffer volume at the pump outlet.

The mathematical model of an axial piston pump was developed in MATLAB/SIMULINK $®$ using S-functions.

S-functions allow the user to include standard blocks in addition to MATLAB script code and custom defined blocks.

Figures 1 and 2 shows simulation plots of swash plate piston force and swash plate moment. The frequency of moment pulse is twice as compared to the pressure pulsation, this is due to the moment changing direction as it crosses the swash plate pivot axis. 


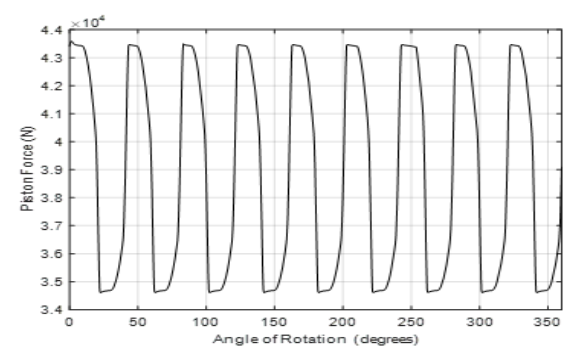

Figure 1: Swash plate Piston force plot

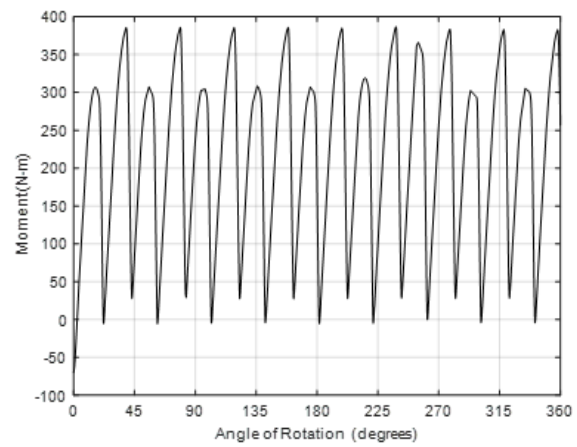

Figure 2: Swashplate moment plot

\subsection{Effect of Groove Length}

When a compressed fluid volume is connected to a discharge port suddenly via a full port area, there will be a large back flow into the piston chamber due to the pressure differential. On the other hand, if the piston chamber pressure is higher than the outlet pressure, a sharp pressure peak will result in output pressure. The optimum would be to exactly match piston pressure with the outlet pressure. This is difficult to achieve. Relief grooves facilitate smooth transition from suction to discharge and discharge to suction ports. Figures 3 and 4 shows swashplate piston force and moment pulsation profiles for the five groove lengths. A reduction in amplitude of swash plate moment pulsation was observed when groove length was increased. Corresponding flow ripple and pressure pulsation plots for five groove lengths are provided in the earlier work by Seeniraj et. al [7].

Their work indicated that relief grooves reduced peak-to-peak value of the flow ripple. Pressure pulsations occur as a secondary effect due to the flow ripple. Variation in the flow ripple will affect the output pressure directly. The frequency of the pulsations is fixed by the prime mover speed. The effect of relief groove on pressure pulsation is far less compared to its effect on flow ripple. The model included a dead volume of one litre connected to the load side of the pump which is typical.

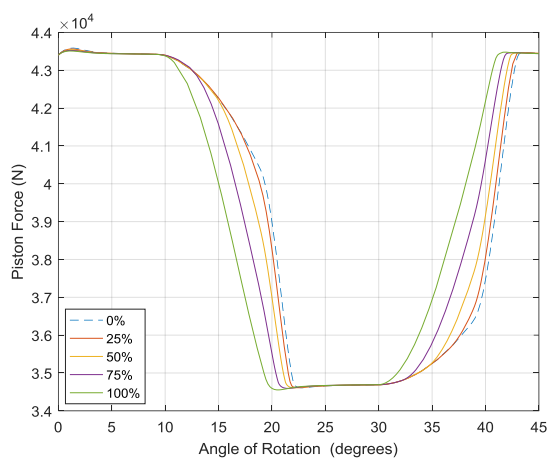

Figure 3: Swash plate piston force for different groove configurations

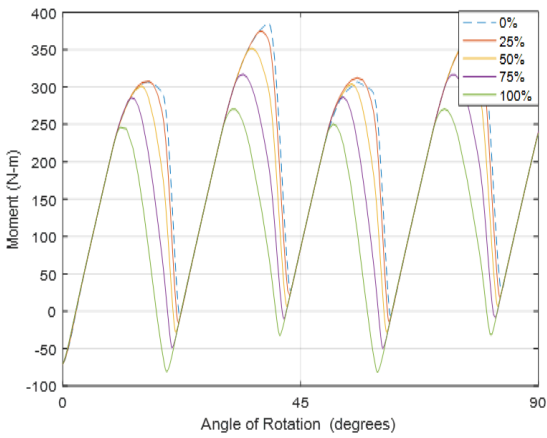

Figure 4: Swash plate moment for different groove configurations

\subsection{Effect of dead centre location and TDC}

In a normal swash plate pump, the pistons reach the end of their stroke(s) at the dead centres where the pistons come to a halt and the direction is reversed. At the dead centres, the displacement of the piston is nearly zero for a small change in the angular rotation. When the piston chamber is connected to the discharge port at this point there is likely to be a reverse flow in the beginning. One of the best solutions to reduce the reverse flow is to compress the fluid to the required outlet pressure before it reaches the discharge port. This is termed as pre-compression. This can be 
accomplished through proper design of the valve plate such that the pistons do not open to the discharge until the fluid is compressed enough to the discharge pressure. The same effect can be achieved by varying the dead centre of the pistons without changing the valve plate profile. Changes in dead centre positions affect both the Top Dead Centre (TDC) and the Bottom Dead Centre (BDC). Typically changes in the TDC affect the suction flow and changes in BDC will change closure timing of the discharge port. A mechanism changing TDC is likely to affect the timing of BDC thus affecting suction port and its closure, and may cause cavitation. These issues are not addressed in this and also in the earlier referenced work.

TDC and BDC lie on the vertical axis of the swash plate. The pistons reach their maximum and minimum stroke position when they reach the TDC and BDC respectively. By advancing, the dead centres are shifted from the vertical axis. When the cylinders move to the actual dead centre position located on the vertical axis, the pistons would have already started moving in the reverse direction. This gives the required precompression.

Maximum reduction in flow ripple was achieved for a case with a full groove length and a five (5)-degree advance in TDC. Advancing the TDC beyond five (5) degrees to seven (7) and nine (9) degrees did not result in a reduction of the peak-to-peak value. Instead, the peak-to-peak value slowly starts to rise. These findings are reported in their work by Seeniraj et al [7]. They also reported that peak-to peak value of the pressure pulsations decreases as TDC was advanced. TDC delay increased the amplitude of pressure pulsations.

Amplitude of swash plate moment shows a decreasing trend when TDC is advanced and the opposite was observed when it is delayed. Figure 6 shows this effect for 5 degree TDC advance compared to its no advance case. Figure 8 shows the effect for 5 degree TDC delay. Figures 5 and 7 shows swash plate force plots for two casesTDC angle of advance (5 degrees) and an angle of delay (5 degrees) respectively. TDC angle of delay accentuates amplitude of pulsation for both swash plate force and moment.

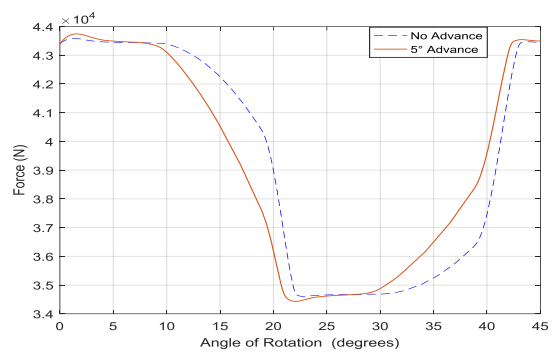

Figure 5: Effect of advancing TDC on swash plate force pulsation

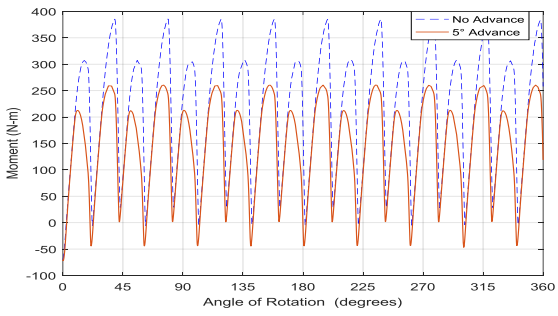

Figure 6: Effect of advancing TDC on swash plate moment pulsation

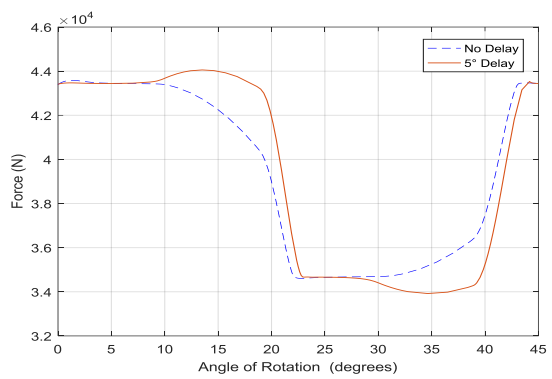

Figure 7: Effect of delaying TDC on swash plate force pulsation

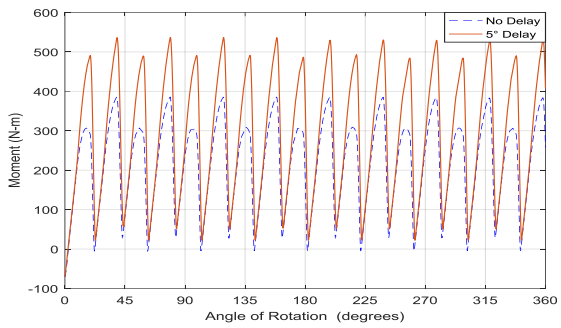

Figure 8: Effect of delaying TDC on swash plate moment pulsation

Figure 9 shows the effect of varying swash plate angle on swash plate moment. Swash plate moment shows an increasing tendency for a decrease in swash plate angle. This is a preferred 
characteristic in terms of swash plate stability. In variable delivery pumps swash plate stroke will normally decrease in response to an increase in load pressure. Figure 10 shows the effect of varying swashplate angle on the force acting on it. It can be noted that as the angle of swashplate increases, so does the force acting on it.

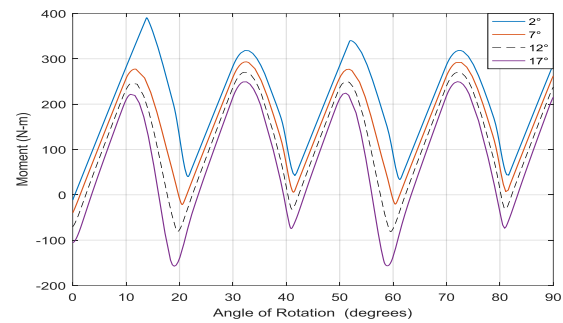

Figure 9: Effect of swash plate angle on swash plate moment

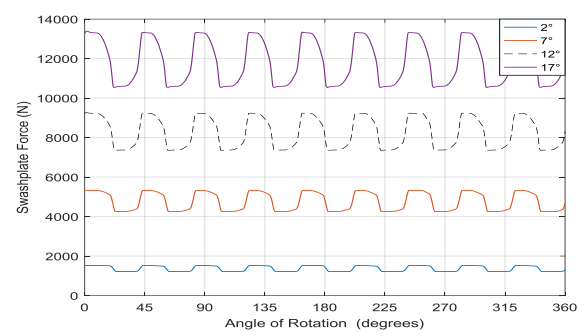

Figure 10: Effect of swash plate angle on swash plate force

Pressure pulsations, resulting effect of flow ripples, depends on the volume available for expansion inside and outside of the pump and in the immediate piping. This volume is referred to as the buffer volume. In the baseline model, a buffer volume of one litre was assumed. Pressure pulsations were simulated using the familiar bulk modulus relationship.

Seeniraj and Chandran [7] in their earlier referenced work examined effect on pressure pulsations due to different buffer volumes, for two cases of groove lengths (zero and full arc length). An increase in buffer volume reduces the amplitude of the pulsations proportionally.

This observation indicates that increasing the buffer volume is a viable option for reducing the amplitude of flow and pressure pulsations. But buffer volume available depends on the pump and the application. Increasing the buffer volume increases the compliance and can lead to an increase in system response time which may not be acceptable.
Figure 11 shows the effect of angle of advance on swashplate moment pulsation, a decrease in amplitude of pulsation was observed.

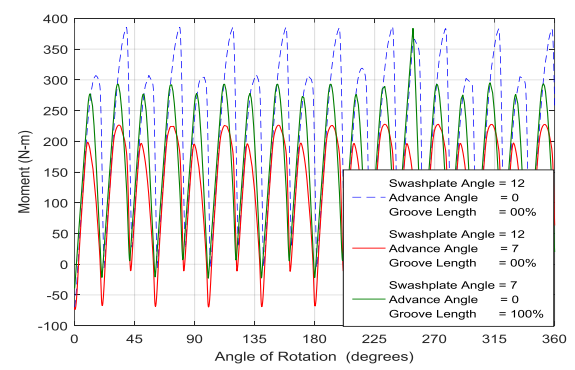

Figure 11: Swash plate moment amplitude reduction

Table 1 lists the effect of groove length and TDC advance angle on peak to peak moment values. It was observed that advancing the dead center position keeps the values low for no groove $(0 \%)$ condition and when groove length is increased, advancing the angle does not help in reducing the peak to peak values.

Table 1: Moment Pulsation Peak-to-Peak Values in $\mathrm{N}-\mathrm{m}$ for different groove lengths and TDC advance angles. Swash plate angle set at 12 degrees ( Base line)

\begin{tabular}{|l|l|l|l|l|l|}
\hline \multirow{2}{*}{$\begin{array}{l}\text { Groove } \\
\text { Length }\end{array}$} & \multicolumn{6}{|l|}{ TDC Advance (degrees) } \\
\cline { 2 - 6 } & 0 & 3 & 5 & 7 & 9 \\
\hline 0 & 456 & 383 & 336 & 303 & 313 \\
\hline 25 & 445 & 377 & 334 & 305 & 318 \\
\hline 50 & 424 & 367 & 335 & 327 & 335 \\
\hline 75 & 387 & 353 & 352 & 354 & 370 \\
\hline 100 & 353 & 363 & 366 & 380 & 393 \\
\hline
\end{tabular}

Figure 12 presents the same data for moment pulsation for changes in groove length and TDC advance angle.

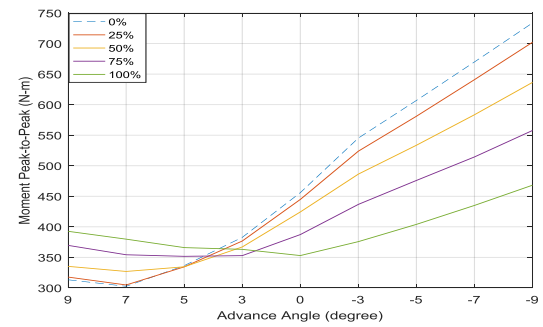

Figure 12: Moment pulsation for different groove lengths and TDC advance angles 
Table 2: Moment Pulsation Peak-to-Peak Values in $\mathrm{N}$-m for different groove lengths and swash plate angles

\begin{tabular}{|l|l|l|l|l|}
\hline \multirow{2}{*}{$\begin{array}{l}\text { Groove } \\
\text { Length }\end{array}$} & \multicolumn{4}{|l|}{ Swashplate Angle (degrees) } \\
\cline { 2 - 5 } & 2 & 7 & 12 & 17 \\
\hline 0 & 542 & 487 & 456 & 438 \\
\hline 25 & 513 & 465 & 445 & 437 \\
\hline 50 & 624 & 429 & 422 & 425 \\
\hline 75 & 591 & 409 & 387 & 409 \\
\hline 100 & 511 & 333 & 354 & 410 \\
\hline
\end{tabular}

Table 2 lists the effect of groove length and swash plate angle on peak to peak moment values. It was observed that the peak to peak value increases with decreasing swashplate angle and when groove length increases, the peak to peak value decreases. A Minimum value was observed for a swash plate angle of 7 degrees.

Figure 13 presents the same data for moment pulsation for changes in groove length and swash plate angle.

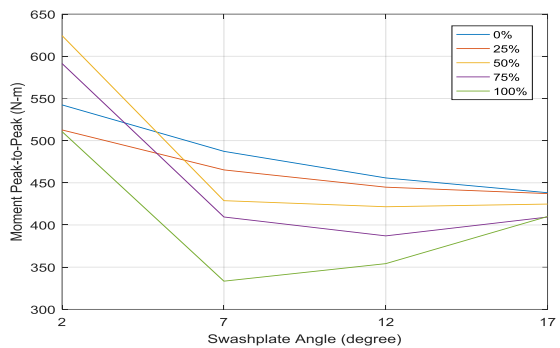

Figure 13: Moment pulsation for different groove lengths and swash plate angles

An examination of Tables 1 and 2 lead to following observations. A change in TDC angle of advancement is more effective compared to groove length change for reducing amplitude of pulsations for both swash plate moment and force. Change in groove length requires hardware modification-change of valve plate. Whereas, angle of TDC advance can be changed easily using the proposed swash plate design using a paired controller. This is the salient feature of this design.

\section{CONCLUSIONS}

A mathematical model of an axial piston pump was developed in MATLAB/SIMULINK ${ }^{\circledR}$ environment using $\mathrm{S}$-functions. This model was exercised to study the effect of groove length and dead centre variations on swash plate moment and swash plate piston forces. Simulation results for pressure and flow pulsations correlated with the earlier work reported by Seeniraj and et al. Swash plate moments exhibited familiar pattern, not altered by introduction of dead centre position.

This study was started with an idea to explore the efficacy of a mechanism to vary dead centre position to minimize pressure and flow pulsations to minimize pump noise. An understanding of moments and forces acting on the swash plate is required to evaluate the proposed design. A simple sketch of the proposed mechanism is given in Figure 14. It employs two wedges separated by a bearing arrangement to minimize friction as a swash plate. When the wedges are rotated by equal amount (angular displacement) with respect to the $\mathrm{Y}-\mathrm{Y}$ axis it provides the required swash plate angular displacement at the TDC and BDC. When the angular displacements of the wedges are unequal, it will provide the swash plate displacement whose TDC and BDC will be off-set from the $\mathrm{Y}-\mathrm{Y}$ axis. This proposed design minimizes the effect of swash plate moments and forces on the actuating mechanism to change swash plate stroke. It is envisioned that this can be effected by a system of spring loaded electric drives acting on each wedge or by a combination spring loaded miniature hydraulic pistons regulated by pressure control valves. Load torque demand on the actuating system will be small due to the bearing arrangement separating two wedges. It is anticipated that this will be a stable system providing required speed of response. A future work will report details of this design and its development.

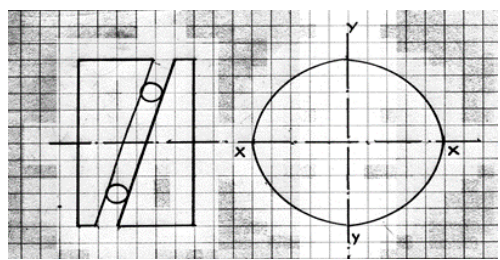

Figure 14: Sketch of a proposed two-wedge Mechanism

\section{REFERENCES}

[1] Becker R J, .1970. Quieting Hydraulic Systems and Components. Society of Automotive Engineers, 700711

[2] Helgestad B O, Foster K, Bannister F K. 1974. Pressure Transients in an Axial Piston Hydraulic 
Pump. Proceedings of Institution of Mechanical Engineers, Vol. 188 17/74

[3] Johansson, A., 2005. Design Principles for Noise Reduction in Hydraulic Piston PumpsSimulation, Optimisation and Experimental verification, Ph.D. Thesis Linkoping University, Sweden.

[4] Pettersson M E, Weddfelt K G and Palmberg J S. 1991. Methods of Reducing Flow Ripple from Fluid Power Pumps - a Theoretical Approach. Society of Automotive Engineers, 911762

[5] Pratin Naik, 2016. Modelling and Simulation of an axial piston pump-a feasibility study for an alternate design for pulsation reduction. M.S. Thesis, Kettering University, Flint, USA.

[6] Schoenau G J, Burton R T, Kavanagh G P. 1990. Dynamic Analysis of a Variable Displacement Pump. ASME Journal of Dynamic Systems, Measurement and Control, Vol. 112, pp. 122132

[7] Seeniraj G K. and Ram S. Chandran, 2011. Study into effect of dead center position on pressure and flow ripples of a variable displacement axial piston swash plate hydraulic pump. The twelfth Scandinavian International conference on Fluid Power, May 18-20 2011,Tampere,Finland.

[8] Yamauchi K and Yamamoto T. 1976. Noises Generated by Hydraulic Pumps and their Control Method. Mitsubishi Technical Review, Vol. 13 \#1, pp. 19-26

[9] Zhang X, Cho J, Nair S S, Manring N D. 2001. New Swash Plate Damping Model for Hydraulic Axial-Piston Pump. ASME Journal of Dynamic Systems, Measurement and Control, Vol. 123, pp. 463-470.

\section{APPENDIX}

\section{The Model}

\section{Piston dynamics}

The pump examined in this study has nine pistons spaced equally in a circular fashion in a cylindrical barrel. The swash plate angle and the pitch circle radius define the movement and the instantaneous position of a piston at any instance. The plane of piston reciprocation lies perpendicular to its plane of rotation. The equations adapted from the model proposed by Burton et al. (5) are used in this study and are given below.

The displacement of a $\mathrm{n}^{\text {th }}$ piston is described as

$$
x_{n}=r \cdot \tan (\alpha) \cdot \sin \left(\theta_{n}\right)
$$

where $r$ is the piston pitch radius and $\theta_{n}$ is the position of the piston with respect to the axis of the plane of rotation.

The velocity can be expressed as

$$
\dot{x}_{n}=r \cdot \tan (\alpha) \cdot \cos \left(\theta_{n}\right) \cdot \omega+r \cdot \sin \left(\theta_{n}\right) \cdot \frac{1}{\cos ^{2}(\alpha)} \dot{\alpha}
$$

The swash plate angle is assumed to be a constant; the velocity of the piston can be simplified as

$$
\dot{x}_{n}=r \cdot \tan (\alpha) \cdot \cos \left(\theta_{n}\right) \cdot \omega
$$

The instantaneous volume inside each piston chamber is given by

$$
V_{n}=V_{0}-A_{p} \cdot x_{n}=V_{0}-A_{p} \cdot r \cdot \tan (\alpha) \cdot \sin \left(\theta_{n}\right)
$$

where $V_{0}$ is the initial volume of the cylinder.

$$
\dot{V}_{n}=-A_{p} \cdot x_{n}
$$

\section{Piston pressure}

The expression for pressure inside each piston chamber can be derived from the definition for bulk modulus.

$$
\begin{aligned}
& \beta=-\frac{d P_{n}}{d V_{n} / V_{n}} \\
& \frac{d P_{n}}{d t}=-\frac{\beta}{V_{n}} \frac{d V_{n}}{d t}
\end{aligned}
$$

Figure 7 shows the schematic of a single piston, with a chamber volume $\mathrm{C}$, flows into and out of the piston chamber $\left(\mathrm{Q}_{\text {in }}\right.$ and $\left.\mathrm{Q}_{\mathrm{dn}}\right)$, leakage flow $\left(\mathrm{Q}_{1}\right)$ and flow due to the movement of the piston. Using the continuity equation for the control volume $\mathrm{C}$, the change in volume can be expressed as

$$
\frac{d V_{n}}{d t}=\left(Q_{d n}+Q_{\text {in }}+Q_{l}+\dot{V}\right)
$$

The volume change in the piston chamber due to piston movement is

$$
\dot{V}=-A_{p} \cdot r \cdot \omega \cdot \tan (\alpha) \cos \left(\theta_{n}\right)
$$

The flow rates $Q_{i n}$ and $Q_{d n}$ can be calculated using the orifice flow rate relationship. 


$$
\begin{aligned}
& Q_{d n}=-A_{d n} C_{d} \sqrt{\frac{2}{\rho}} \sqrt{\left|P_{d}-P_{n}\right|} \operatorname{sign}\left(P_{d}-P_{n}\right) \\
& Q_{i n}=-A_{i n} C_{d} \sqrt{\frac{2}{\rho}} \sqrt{\left|P_{i}-P_{n}\right|} \operatorname{sign}\left(P_{i}-P_{n}\right)
\end{aligned}
$$

The leakage flow rate, $Q_{l}$, was approximated using the leakage coefficient $C_{l}$ and is proportional to the pressure inside the piston chamber.

$$
Q_{l}=P_{n} \cdot C_{l}
$$

Substituting equations $8-12$ in equation 7 , an expression for pressure, $\mathrm{P}_{\mathrm{n}}$, was obtained.

Valve plate profile was modeled using the data from an earlier work. Relief grooves are provided at the beginning of both suction and discharge ports. If there are no grooves, then the 9 degrees of valve land provides pre-compression. This configuration of valve plate accommodates the relief groove and pre-compression. The maximum groove length is fixed at the chosen value (9 degrees) because further increase in groove length might not offer any considerable reduction. The simulated groove profile is shown below in Figure A-2.

Table A- 1. System Parameters - Numerical Values

\begin{tabular}{|l|l|}
\hline Fluid properties & $\beta=1.2 \mathrm{e} 9 \mathrm{~Pa}$ \\
& $\rho=878 \mathrm{~kg} / \mathrm{m}^{3}$ \\
\hline Piston & $\mathrm{A}_{\mathrm{p}}=789.2 \mathrm{e}-6 \mathrm{~m}^{3}$ \\
& $\mathrm{C}_{\mathrm{d}}=0.62$ \\
& $\mathrm{C}_{\mathrm{l}}=4.6 \mathrm{e}-12 \mathrm{\textrm {m } ^ { 3 }} / \mathrm{s} / \mathrm{Pa}$ \\
& $\mathrm{N}=9$ \\
& $\mathrm{R}=0.06731 \mathrm{~m}$ \\
& $\mathrm{~V}_{\mathrm{o}}=65.39 \mathrm{e}-6 \mathrm{~m}^{3}$ \\
\hline wash plate angle & $\alpha=12$ degrees \\
\hline Prime mover & $\omega=210 \mathrm{rad} / \mathrm{s}$ \\
\hline
\end{tabular}

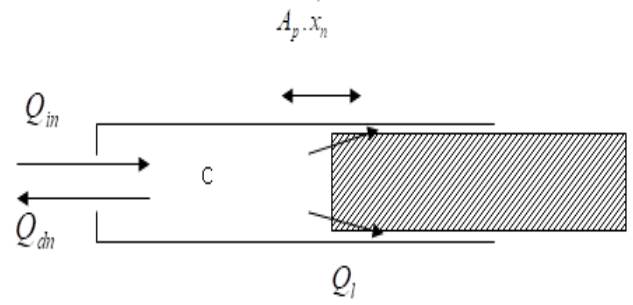

Figure A-1: Schematic of a single piston and its associated flows

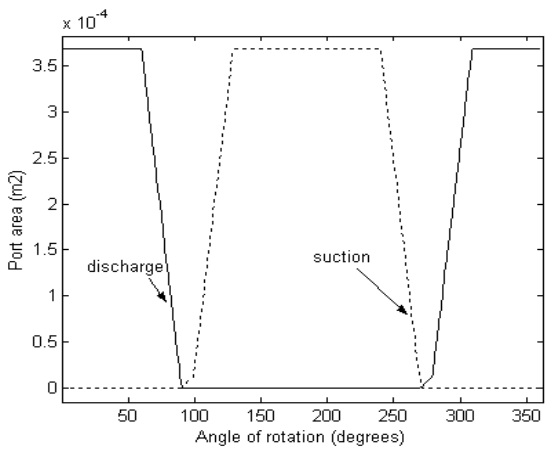

Figure A-2: Discharge/ suction port areas.

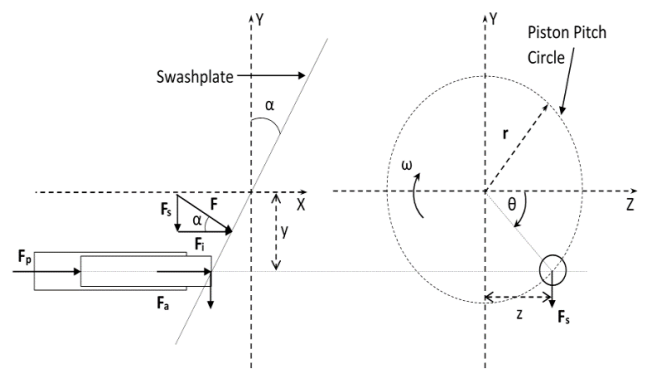

Figure A-3: Swash plate forces

$F_{i}=F_{P}+F_{a}$

$F_{a}=m_{P} \cdot \ddot{x}_{i}=-m_{P} \cdot r \cdot \tan (\alpha) \cdot \sin \left(\theta_{i}\right) \cdot \omega^{2}$

$F_{i}=F_{P}+F_{a}$

$F_{S}=F_{i} \cdot \tan (\alpha)$

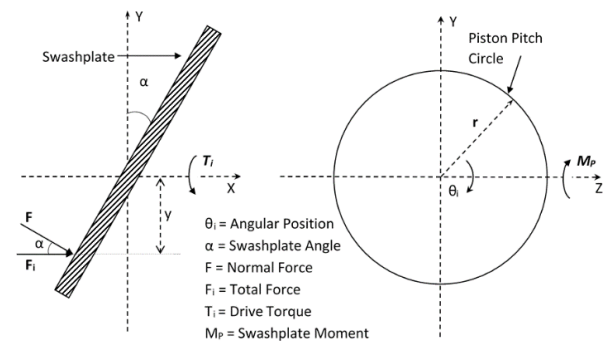

Figure A-4: Force, Torque and Moment in a Pump.

$$
\begin{gathered}
M_{P}=F \cdot \frac{y}{\cos (\alpha)}=\frac{F_{i}}{\cos (\alpha)} \cdot \frac{r \cdot \sin \left(\theta_{i}\right)}{\cos (\alpha)} \\
=F_{i} \cdot r \cdot \frac{\sin \left(\theta_{i}\right)}{\cos ^{2}(\alpha)}
\end{gathered}
$$




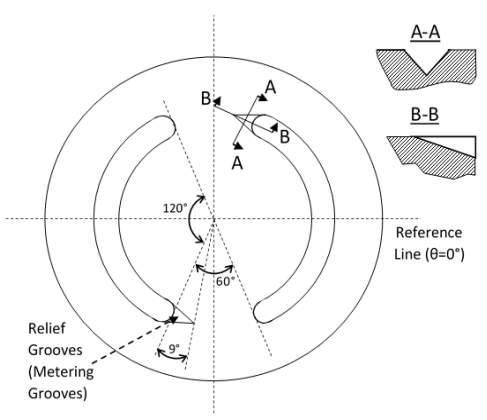

Figure A-5: Valve plate details

\section{NOMENCLATURE}

$\alpha \quad$ swash plate angle (degrees)

$\beta \quad$ fluid bulk modulus $(\mathrm{Pa})$

$\rho \quad$ fluid density $\left(\mathrm{kg} / \mathrm{m}^{3}\right)$

$\theta \quad$ angle of rotation (degrees)

$\omega \quad$ pump speed $(\mathrm{rad} / \mathrm{s})$

$\mathrm{A}_{\mathrm{d}} \quad$ discharge port area $\left(\mathrm{m}^{2}\right)$

$\mathrm{A}_{\mathrm{i}} \quad$ suction port area $\left(\mathrm{m}^{2}\right)$

$A_{v} \quad$ load orifice valve area $\left(\mathrm{m}^{2}\right)$

$\mathrm{C}_{\mathrm{d}} \quad$ coefficient of discharge

$\mathrm{C}_{\mathrm{l}} \quad$ leakage coefficient $\left(\mathrm{m}^{3} / \mathrm{s} / \mathrm{Pa}\right)$

$\mathrm{P} \quad$ pump outlet pressure $(\mathrm{Pa})$

$\mathrm{P}_{\mathrm{d}} \quad$ discharge pressure $(\mathrm{Pa})$

$\mathrm{P}_{\mathrm{i}} \quad$ suction pressure $(\mathrm{Pa})$

$\mathrm{P}_{\mathrm{n}} \quad$ pressure inside piston chamber $(\mathrm{Pa})$

$Q_{\text {dn }}$ discharge flow rate $\left(\mathrm{m}^{3} / \mathrm{s}\right)$

$\mathrm{Q}_{\text {in }} \quad$ suction flow rate $\left(\mathrm{m}^{3} / \mathrm{s}\right)$

$\mathrm{V}_{\mathrm{b}}$ buffer volume $\left(\mathrm{m}^{3}\right)$

$\mathrm{V}_{\mathrm{o}} \quad$ piston initial volume $\left(\mathrm{m}^{3}\right)$ 